The Effects of Consumer Bliss on Welfare Economics Author(s): William A. Barnett

Source: Journal of Economic Issues, Vol. 7, No. 1 (Mar., 1973), pp. 29-45

Published by: Association for Evolutionary Economics

Stable URL: http://www.jstor.org/stable/4224196

Accessed: 03/03/2014 14:41

Your use of the JSTOR archive indicates your acceptance of the Terms \& Conditions of Use, available at http://www.jstor.org/page/info/about/policies/terms.jsp

JSTOR is a not-for-profit service that helps scholars, researchers, and students discover, use, and build upon a wide range of content in a trusted digital archive. We use information technology and tools to increase productivity and facilitate new forms of scholarship. For more information about JSTOR, please contact support@jstor.org. 


\section{The Effects of Consumer Bliss on Welfare Economics}

\section{William A. Barnett}

This article explores the impact of consumer satiation on the functioning of a private ownership economy free from market imperfections. Kenneth Arrow has proved that consumer satiability has no effect on the Pareto optimality of competitive equilibria; ${ }^{1}$ his conclusion is disproved by counter-example and his error is isolated. Arrow's model is corrected and then related to a concept introduced by David Gale. ${ }^{2}$ Although the choice of the mainstream paradigm is dictated by Arrow's assumptions, the corrected model provides one basis for illustrating issues raised by radical as well as some liberal economists.

\section{Saturation (Satiation) Consumption Bundles}

Although in many areas of economic analysis consumer insatiability (nonsaturation) is assumed, the applicability of that assumption in the field of welfare economics is questionable. In that field the demonstration that every competitive equilibrium is Pareto optimal is purported to obtain for any arbitrary distribution of wealth, subject to what are presumed to be weak qualifications. To maintain that there is no one in the United States whose consumption desires would be satiated if he were allocated half of the nation's wealth is to

The author is a graduate student at Carnegie-Mellon University. Substantial simplifications and clarifications were made possible by comments received from David Cass. The author also is indebted to Leonard Rapping for pointing out an erroneous argument contained in an early draft and for assisting in the organization of the final draft. 
affix to the theorem a qualification which is far from weak. Conversely, to accept the possibility of the existence of bliss points (satiation consumption bundles ${ }^{3}$ ) does not violate conditions for economic "perfection," since the properties of bliss points are not in conflict with assumptions of the lack of externalities, the selfishness of preferences, the perfection of knowledge, or the perfection of rationality.

The concept of consumer satiability not only is of importance in theoretical welfare economics, but also has been used widely by old and new left economists, a few contemporary liberals, and some well-known earlier economists. ${ }^{4}$ Perhaps the clearest applications of satiability are in the writings of the classical utopians and the speculations of the Marxist theory of pure communism, which postulates uniformly zero prices in an environment devoid of any rationing devices. ${ }^{5}$ The relevancy of satiability to new left views is illustrated by Michael Zweig's assertion that "marginalism is appropriate as a technique under two fundamental conditions: 1) scarcity; 2) a desire for maximization (or minimization). . . . Who will be the economists helping to undo the artificial rat-race? Who will be the operations-analysts in the hippie communities? Who will analyze a world in which more stuff is not better? In the absence of effective scarcity, marginalism loses its relevance." 6 John Kenneth Galbraith's applications of the concept of consumer satiability are widely known, ${ }^{7}$ as are those of some ecologists.

\section{The Issue}

Although all neoclassical welfare proofs and some set-theoretic welfare proofs assume nonsaturation, Arrow has demonstrated the Pareto optimality of competitive equilibria in a private ownership economy through a remarkably simple proof, which is dependent in no way upon insatiability assumptions. ${ }^{8}$ Not excluding the possibility of bliss points, Arrow's proof is of particular interest and relevance. The contention of this article is that Arrow's proof is based upon a definition which is valid only when consumers are insatiable. Once this definition has been corrected, Pareto optimality no longer need hold for competitive equilibria.

In 1955 David Gale published an important article, "The Law of Supply and Demand." ${ }^{9}$ Gale, like Arrow, considered the possibility of bliss points, but Gale also correctly identified the possibility of the existence in equilibrium of what he called "savings"- -goods supplied by the economy but never consumed. Since savings generally are viewed as having been motivated by a taste for future consumption, 
Gale's term might more descriptively have been "savings by default." When referring to Gale's savings, this article generally will use the term hoarding. Gale's view is presented in a deceptively simple example in which he postulates the existence of a pure exchange economy containing two persons, $\mathrm{Mr}$. A and $\mathrm{Mr}$. B, and a quantity, $Q$, of one good. Mr. A is assumed to own the entire stock, while $\mathrm{Mr}$. B owns nothing. Mr. A is satiable in the one good at a consumption level of $P$, which is assumed to be less than the total stock, $Q$; $\mathrm{Mr} . \mathrm{B}$ is insatiable.

Since the model has one good and no labor, the single good trivially is chosen as the numeraire with a price of one. No other good existing to be sacrificed, and no production existing in the model, free disposal is assumed implicitly. Since the model is one of pure exchange, no need exists to consider the merits of a profit maximization assumption. $\mathrm{Mr}$. A will choose to consume at his saturation level and will dispose of the remainder of the stock, that is, of $Q-P$. Mr. B having nothing to offer, and Mr. A. wanting nothing more, Mr. B. will have no choice but to consume nothing. This equilibrium allocation is not Pareto optimal: The allocation of $P$ units to Mr. A and $Q-P$ units to $\mathrm{Mr}$. B is a Pareto superior allocation. Clearly Gale's solution to that trivial pure exchange problem is correct.

Gale used his simple example as a means of demonstrating the need for a no savings assumption in his welfare proof rather than to investigate the welfare effects of relaxing that assumption. Although his welfare proof related to a pure exchange model in which income in excess of the satiation level is not permitted in equilibrium, Gale carefully qualified the conclusion of his welfare theorem to apply solely to the single "important special case of a model with no savings." ${ }^{10}$ Arrow, on the other hand, did permit the existence of equilibrium income in excess of satiation, ${ }^{11}$ but without recognizing the complications illustrated by Gale.

Since the meanings of profits, price, and market in Gale's no production, one good, and no exchange example are not clear, extensions of Gale's illustration are required to reveal the impact of satiation on welfare in a market economy. Such extensions will be developed in detail below.

To exhibit the welfare effects of bliss points, a stationary pure exchange economy will be considered. ${ }^{12}$ The case of a bliss point in a consumer's preferences is illustrated in Figure 1, onto which two budget constraints have been superimposed. $P$ is a bliss point surrounded by concentric indifference curves with a larger radius corresponding to a lower level of satisfaction. Although along budget 


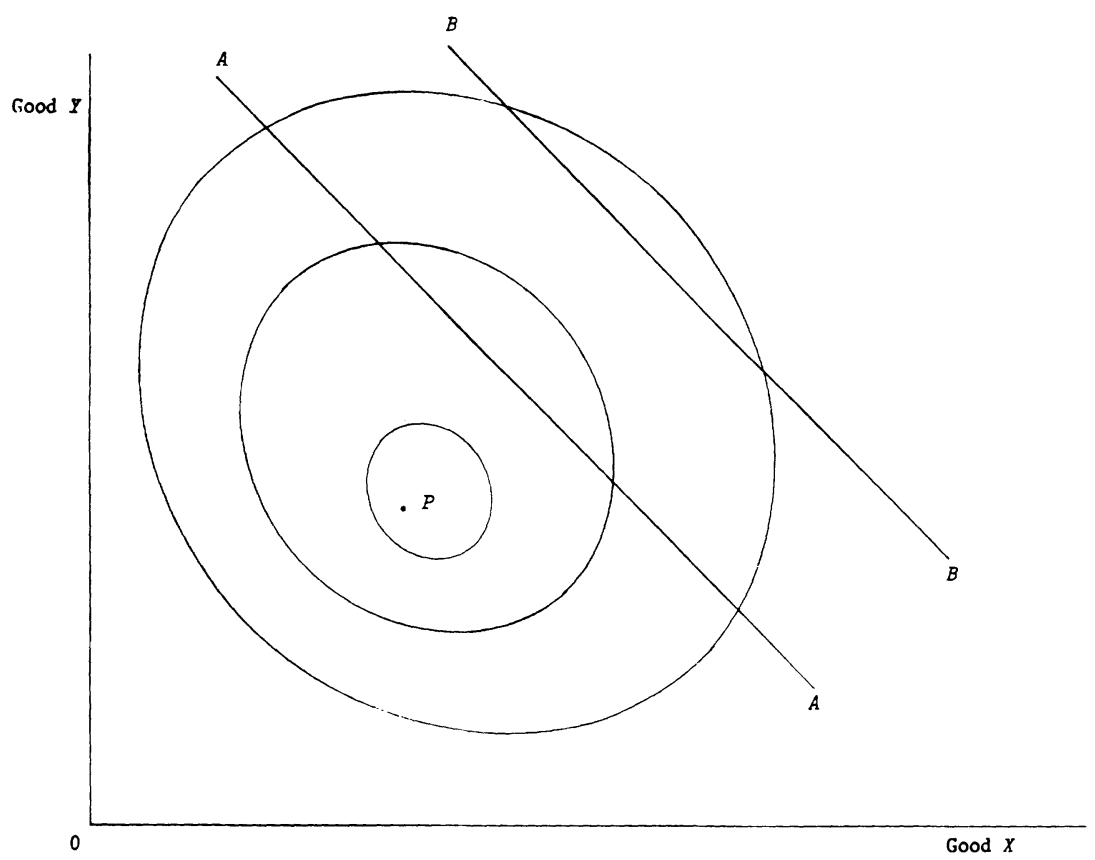

Figure 1: Consumer Bliss Point

constraint $B B$ the consumer is receiving greater income, perhaps from corporate profits, than along budget constraint $A A$, in either case he will choose to consume at his bliss point $P$. In neither case will he consume all of his income.

For an example of the effects of bliss points on the welfare properties of competitive equilibria, consider Figure 2. It illustrates a model of pure exchange with two commodities and two persons. The initial endowment allocation is at point $E .{ }^{13} \mathrm{Mr}$. A has a bliss point at $Q$, while $\mathrm{Mr}$. B is satiated by consumption quantities in excess of those available in the simple economy. The price ratio having been set at the level defining the budget line $D D, \mathrm{Mr}$. B will wish to consume at $M$. Mr. A can achieve bliss by trading at the market to acquire the bundle at $M$ and then, off of the market, by consuming at $Q$ while disposing of what remains of the quantity of good $X$ possessed at $M \cdot{ }^{14}$ For each good, the quantity supplied at the market equals the quantity demanded at the market. Knowing nothing of the disposal decision, the price-setting "auctioneer" views each market as having been cleared. Hence consumption at $M$ by $\mathrm{Mr}$. B and consumption at $Q$ by $\mathrm{Mr}$. A define an equilibrium market allocation. 
Clearly the transfer of the discarded goods to Mr. B would generate a Pareto superior allocation.

Although this example illustrates that a competitive equilibrium need not be Pareto optimal, Arrow's proof purports to demonstrate that such a result is impossible, even if an attainable bliss point exists. Arrow's proof holds since, by his definition, a competitive equilibrium can exist only if the aggregate value of goods supplied ("profits"), determined through their maximization, is equal to the value of goods consumed. Figure 2 violates that equality condition. One possible source of Arrow's definition is the strong (equality) form of Walras's Law, derived by summing the budget constraints in equality form. But the equality form of the budget constraint itself is a conclusion following from two assumptions: the inequality form of the budget constraint (which is an assumption ${ }^{15}$ ), and the insatiability of preferences. Since insatiability is not assumed in Arrow's theorem, consumers need not exhaust their budgets and the strict form of Walras's Law need not apply. ${ }^{16}$

Another possible argument exists favoring the equality in equilibrium of the value of goods supplied and of those consumed. It might be argued that the market for a nonfree good is cleared only if the quantity of the good supplied equals the quantity consumed. When satiability is permitted, that view would ignore the fact that equilibrium

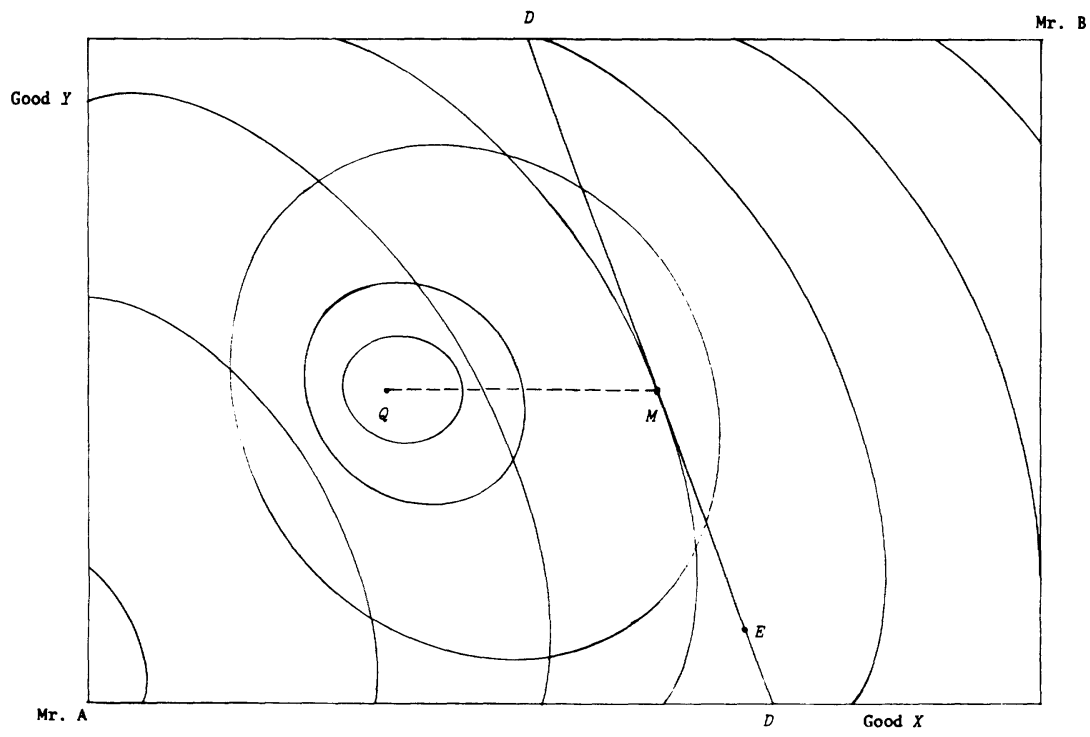

Figure 2: Pure Exchange Economy 
consumption and market demand need not be equal; but the auctioneer who sets the prices is concerned solely with the equality of supply and demand at the market. The auctioneer has no knowledge of or interest in consumption or disposal of goods off of the market. He knows only of their sum: market demand. As a result, with bliss points in existence, a possibility Arrow permits, all markets can be cleared and all prices can be in equilibrium without the quantity of each nonfree good supplied by the economy equaling the quantity of that good consumed by consumers. Figure 2 provides an illustration of that fact. Arrow's definition of equilibrium is based upon an equality that is not applicable.

In the above example, one Pareto optimal equilibrium could be attained: Mr. A could agree to transfer his unconsumed quantity of good $X$ to $\mathrm{Mr}$. B as a gift. The point is that, contrary to Arrow's assertion, such an equilibrium need not be unique. Indeed, the efficient allocation is only one among an uncountably infinite number of inefficient equilibria. In practice a choice between nonunique equilibria can be made only on the basis of the probable direction of deviations from the model's assumptions and on the basis of the model's robustness to such deviations. Since these choices are not relevant to theory, they will be leit to later sections on applications.

\section{The Model with Production}

To illustrate the effect of bliss on economic welfare when production exists, consider the case of a stationary, two person, one good, one industry (hereafter referred to as the firm) economy; initial stocks of the consumer good do not exist, ${ }^{17}$ and the firm is owned through inheritance solely by one of the two persons. The one laborer-manager, viewed as having no initial endowment, exchanges his labor for quantities of the one good at the rate of exchange defined by the wage rate. The owner, on the other hand, views work as severely demeaning to a person in his position-he would rather starve than work. Furthermore, he is assumed to be satiable in the single good, $X$, at that consumption level indicated by point $B$ in Figure 3 ; his level of satisfaction declines as his consumption level increases or decreases along the Good $X$ axis from his bliss point. ${ }^{18}$ In Figure 3 the production function is shown as $O T$, and several of the laborer-manager's indifference curves have been superimposed upon the first quadrant. The laborer-manager is assumed to be locally insatiable at the wage rates to be considered.

Now let the wage rate be represented as the slope of the ray $O S$ in Figure 4. The laborer-manager will wish to consume at $R$ and 


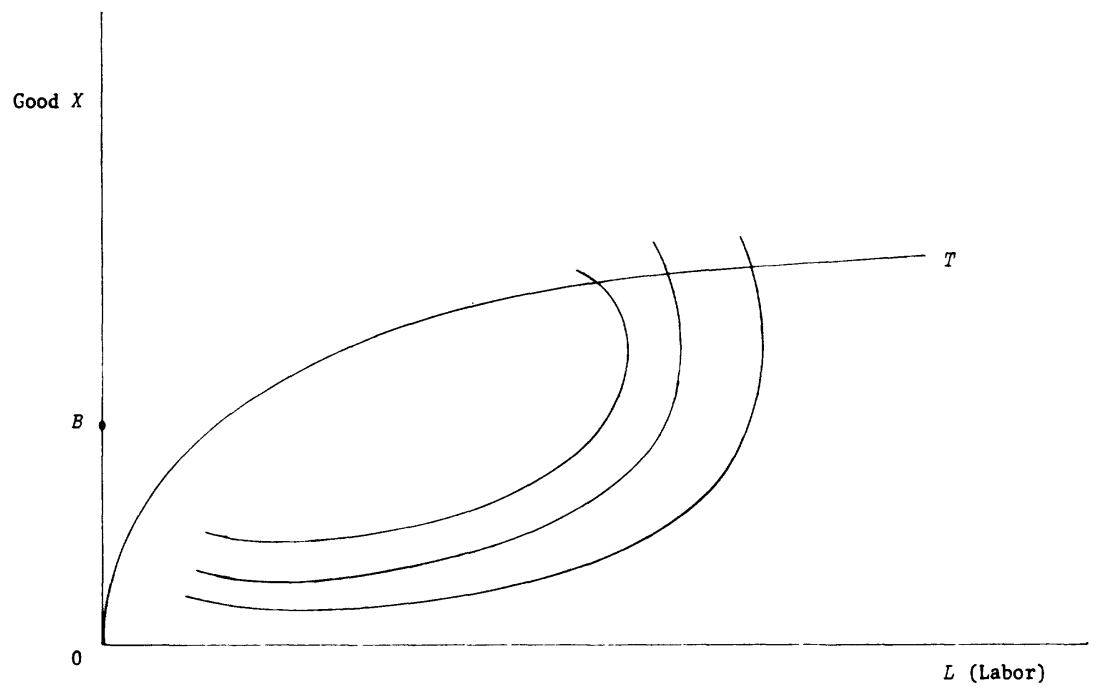

Figure 3: Technology and Preferences

to supply $L^{*}$ units of labor. The firm chooses the feasible production point that will maximize the owner's satisfaction at the given wage rate. Depending upon his views concerning the function of entrepreneurship, the reader can decide upon the means by which the firm's decision is effected. ${ }^{19}$ The cross-hatched area within KNM in Figure 4 contains the set of possible solutions to the manager's decision problem. The half-line $B S^{\prime}$ is parallel to the ray $O S$. All points along the half-line $B S^{\prime}$ and, therefore, all points along the segment $K M$ yield a profit level of $O B$ measured in units of the good $X$. If the firm were to operate anywhere along $K M$, the owner would consume out of profits at $B$, his saturation level. Consuming at his bliss point, the owner could be no happier. Consider point $R^{\prime}$ on the segment $K M$ as a possible production point in a competitive equilibrium. Since all points along $K M$ permit the owner to attain unqualified economic bliss, each such point must maximize the owner's utility at the given wage rate; hence the point $R^{\prime}$ must. So $L^{*}$ is in the labor demand set at that wage, while $X_{2}$ is in the product supply set.

At the given wage rate, the laborer-manager's demand for the consumption good is $X_{1}$, while the owner's demand for the consumption good is $B$. The total demand for the consumption good is $B+X_{1}$ $=B+\left(X_{2}-B\right)=X_{2}$, a quantity which has been shown to be in the product supply set. In addition, at the given wage rate, the 


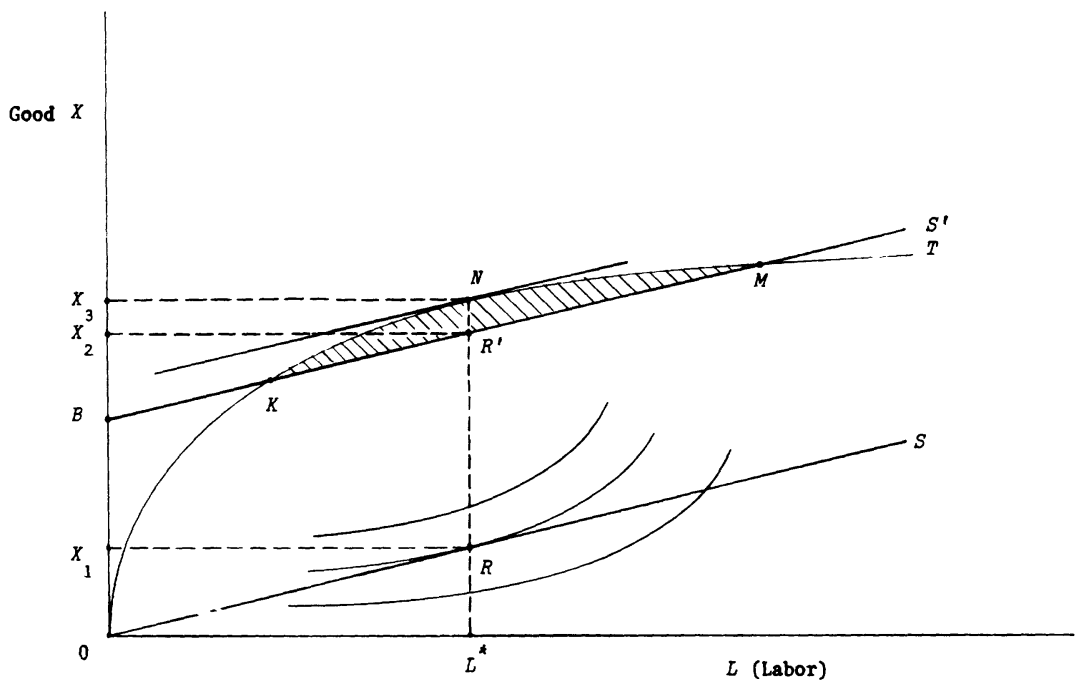

Figure 4: Economy with Production

laborer-manager's labor supply is $L^{*}$, which is in the labor demand set. Hence all markets are cleared. Furthermore, the laborer-manager's utility is maximized for the given wage rate, while the owner's utility is maximized for the given wage rate and the given technology. All behavioral assumptions are satisfied. ${ }^{20}$ The given wage rate, the quantity of labor at $L^{*}$, and the consumption allocation of $B$ to the owner and of $X_{1}$ to the laborer-manager define a market equilibrium in the private ownership economy. ${ }^{21}$

Suppose, for example, that a government were to nationalize the firm. The government then could supply the former owner with his bliss consumption bundle on the condition that he continue to make any entrepreneurial decisions that he may have made as owner but with the explicit requirement that profits be maximized. Leaving the wage rate unchanged, the government could set the production level at $X_{3}$ and provide the laborer with a lump-sum bonus equal to $X_{3}$ - $X_{2}$. The owner is as blissfully happy as before, while the laborermanager is happier than ever. The new solution being Pareto superior to the old solution, the market equilibrium is not Pareto optimal. ${ }^{22}$ Furthermore, the externally controlled equilibrium, unlike the market equilibrium, ${ }^{23}$ maximizes the firm's and thereby the economy's profits. This example indicates that profits need not be maximized in a competitive equilibrium. Since that result may seem surprising, the 
applicability of the usual arguments for profit maximization will be considered.

In Gerard Debreu's highly explicit set-theoretic models, the transfer of ownership claims is not possible. Although not always as evident, this characteristic is common to set-theoretic models in general, as has been made clear by Tjalling Koopmans: "A model that assigns specific production sets exhibiting decreasing returns to scale to a given number of producers is suitable only for tracing the effects of a given distribution of nontransferable knowledge and of implied indivisible resources. It cannot serve for discussing the best utilization of all available knowledge and resources when there are no impediments to their diffusion or transfer of control." ${ }^{24}$ Since for theoretical as well as empirical reasons decreasing returns to scale generally are believed to be a common characteristic of production functions, Koopmans's observation is highly relevant and will be central to much of the following discussion.

In the market solution illustrated in Figure 4, one might presume that by purchasing the firm the laborer-manager could improve his lot. Since such ownership transfers are not permitted within settheoretic models, the possibility need not be considered. However, in this case the limitations of the set-theoretic method are not serious; since the owner can achieve no higher satisfaction than that which already is available to him, the laborer can offer nothing that would ensure the acceptance of an offer. The continued ownership of the firm by the original owner defines a legitimate stationary allocation of ownership claims.

As described by Koopmans, the number of firms is fixed in set-theoretic models. Hence in Figure 4 no consideration need be given to the possibility of the laborer-manager's building a new firm even if he possessed the necessary wealth. This limitation of settheoretic models need not overly restrict the applicability of Figure 4. Perhaps the single owner monopolizes required entrepreneurial ability; perhaps he owns the total supply of some scarce factor required in the production of the one good; or perhaps he has acquired a patent on the product.

A common argument in favor of the profit maximization assumption is that firms which do not maximize profits will fail through the competition of more efficient firms. Since in Figure 4 all profits are imputed as rent to the scarce factors monopolized by the firm's owner, those factors are underpaid by the inefficient operation of the firm. No other firm being able to purchase the monopolized factors, no other firm could benefit from their underpayment. Furthermore, all 
economic rent having been imputed to the scarce factors, no profits remain to serve as an incentive to entry through the use of other nonmonopolized factors. In any event, the basic set-theoretic assumption of a fixed number of firms excludes the possibility of entry by any means.

But suppose that in the unregulated market economy the laborermanager were to attempt to reap the benefits of the controlled equilibrium by setting the firm's output at $X_{3}$ rather than $X_{2}$. The added output would accrue as profits to the owner, who would dispose of them. Without access to governmental authority, the laborer-manager would have no means of acquiring the added production from the satiated owner; as a result he would not be motivated to prefer production at $N$ to production at $R^{\prime}$.

As indicated in the previous section, Arrow's assumption of the equality of the value of goods supplied and of those consumed should be dropped from the definition of equilibrium. This section indicates that the assumption of profit maximization also might be dropped from that definition. ${ }^{25}$ Although the elimination of profit maximization would add realism to the definition of equilibrium, no fundamental error would result if profit maximization were retained, since profits in excess of those desired would not be consumed.

\section{Applications}

As noted earlier, Galbraith as well as old and new left economists have dealt with applications for which this article provides a theory; a further application discussed by Joseph Schumpeter will be considered below. Common to all of these views is the conviction that satiation is an affluent society problem. As will be made clear in this section, satiation has its most unfavorable effects on the operation of a private ownership economy when the distribution of wealth is severely unequal, a possibility which can exist in the most nonaffluent societies of the Third World as well as in the most superaffluent societies of the future.

In previous sections, the discussion has been strictly formal to permit adherence to the assumptions of Arrow's model and to provide an extension of Gale's example sufficient to demonstrate the relation of satiation to theoretical welfare economics. No market imperfections were assumed. To construct the desired counter-examples, no uniqueness proof was required, and no uniqueness claim was made; however, in some of the widely known applications of the satiability concept, deviations from a perfect market assumption could be viewed as implicit, since uniqueness is commonly suggested. 
The crucial assumption in any attempt to discriminate between nonunique equilibria in an economy containing satiated consumers is the traditional one of selfish preferences. According to that perfect market assumption, a consumer's preferences are related solely to his own consumption; he is not influenced in any way by the consumption bundles attained or desired by any other consumer. Alternatively, if consumers were insatiably charitable, otherwise satiated consumers willingly would donate excess goods to any persons not yet satiated. Deviations from selfishness in the opposite direction can be achieved by permitting envy, the assumption of relative wants. With respect to moderate wealth transfers, charitableness may well be a plausible assumption, ${ }^{26}$ even within a competitive economy; but with respect to the massive voluntary shifts in wealth and social class that would be required to eliminate economic waste in most common applications of satiability, envy is a far more reasonable one. The assumption of envy in such a model could be viewed as permitting insatiability in status and prestige concomitant with satiability in goods and services. ${ }^{27}$

\section{Economic Development}

In a tradition-bound society where the rich are very rich and the poor are very poor, where the name Calvin is unknown, ${ }^{28}$ where the fixed factor land is held in few hands, and where education is the prerogative of the few, perhaps entrepreneurs may be more interested in protecting their privileged positions than in promoting initiative in peasant-farmers or in employees. In such a society one might expect to find huge bureaucracies in which the buck is always passed and no one rocks the boat. Firmly entrenched in the upper class, the nation's wealth owners perceive the existence of no higher social status to which to aspire and allow "savings by default" in such forms as hoards of jewels and gold to accumulate without limit. ${ }^{29}$

In an economy having a high pure interest rate, the consistent channeling of savings away from high yield, low risk assets is evidence that the utility maximization of investors is not representable by a profit maximization process. ${ }^{30}$ Whatever physical capital might be brought into the economy through investment by foreigners is not of basic value in solving the country's development problems; such capital is mobile and could have been purchased by the country itself if its resource owners possessed the necessary motivation to invest their hoards of savings by default in imported capital goods. The scarcity of the mobile factor capital is a symptom of the country's 
problem. The cause is the inefficient use of the nation's closely held entrepreneurial ability, land, patents, and other fixed factors.

\section{The Future}

In his Capitalism, Socialism, and Democracy, Schumpeter expressed a once fashionable concern about the effect of future affluence upon the "typically bourgeois kind of profit motive" and thereby upon "the efficiency of the capitalist engine of production." ${ }^{31} \mathrm{He}$ predicted that the entrepreneur eventually would discover that his aspirations, both social and economic, had been satisfied, and that his support for the capitalist order had begun to wane. With his children not sharing their predecessors' entrepreneurial drive toward continued economic accumulation and acquisition, economic stagnation would be followed by a weakly opposed conversion to socialism.

Figure 4 provides an illustration of the pretransition stage, in which the inherited income of a nonmaterialistic entrepreneur is in stationary stagnation at a saturation level, his savings are zero, and economic efficiency is low. The incentive for the change to socialism emanates from the preferences of the laborer-manager, while the entrepreneur, to be supported at a saturation level after the transition, offers no resistance to the conversion: Envy is not assumed.

\section{Conclusion}

The assumption relaxed by this article is insatiability. The relation between that assumption and those of profit maximization and market clearing has been considered. Through extensions of Gale's simple example, the analysis demonstrates that competitive equilibria in a private ownership economy need not be Pareto optimal. ${ }^{32}$ The possibility of the existence of non-Pareto optimal equilibria in an unregulated laissez-faire economy stems from the society's inherently rigid allocation of its wealth. In reaching this conclusion, the paper's methods of analysis, criteria of optimality, and paradigmatic framework of discussion are in all instances those reflecting most favorably upon the performance of a private ownership economy: No market imperfections are assumed.

\section{Notes}

1. Kenneth Arrow, "An Extension of the Basic Theorems of Classical Welfare Economics," in Proceedings of the Second Berkeley Symposium (Berkeley: University of California Press, 1951), pp. 507-32. Arrow's work is presented and discussed in James Quirk and Rubin Saposnik, 
Introduction to General Equilibrium Theory and Welfare Economics (New York: McGraw-Hill, 1968), chap. 4.

2. David Gale, "The Law of Supply and Demand," Mathematica Scandinavia 3 (1955): 155-59.

3. Those uncomfortable about the concept of satiation might consider Milton Friedman's criteria for goodness of an economic model-explanatory and predictive power of the model and fewness and simplicity of the assumptions. Reality of the set of assumptions is viewed as a vice.

For those with a taste for controlled experiments, empirical evidence of the possibility of existence of bliss points can be found in the remarkable economic success of the Harmony Society at Old Economy, within which goods were distributed free, without rationing of any kind. The reason for the communal society's ultimate dissolution can be traced to the society's religious belief in celibacy, a belief which doomed the society from the start to the lifetime of one generation. The existence of bliss points is not in conflict with characteristics intrinsic to "human nature."

On theoretical grounds the rapidly growing literature on the allocation of leisure time can be used to explain and prove the existence of points or regions of bliss. Since goods are consumed jointly with time and since time is limited to twenty-four hours per day, an upper bound exists to the rate of consumption goods. The literature on the subject originated $\mathrm{w} \rightarrow$ Gary Becker, "A Theory of the Allocation of Time," Economic Journal 75 (1965): 493-517. In the more traditional model used by Arrow, the effects of such time constraints have been absorbed into the utility function. Satiation is the means by which the resulting induced utility function reflects the upper bound on consumption. For an explicit discussion of the time constrained consumption choices of the wealthy, see Arther De Vany, "Time in the Budget of the Consumer: The Theory of Consumer Demand and Labor Supply under a Time Constraint," Professional Paper No. 36 (Arlington, Va.: Center for Naval Analyses, June 1970), pp. 97-99.

4. According to Max Weber, "a man does not 'by nature' wish to earn more and more money, but simply to live as he is accustomed to live and earn as much as is necessary for that purpose." Alfred Marshall formulated as a law of economic behavior that "there is an endless variety of wants, but there is a limit to each separate want. This familiar and fundamental tendency of human nature may be stated in the law of satiable wants or of diminishing utility." Weber's statement can be found in his The Protestant Ethic and the Spirit of Capitalism (New York: Charles Scribner's Sons, 1958), p. 60, while Marshall's discussion can be found in his Principles of Economics, 7th ed. (London: Macmillan, 1916), p. 93.

5. An extensive discussion of the central importance of the theory of pure communism to contemporary radical economics is contained in Howard Sherman's Radical Political Economy (New York: Basic Books, Inc., 1972), chaps. 22 and 23. Also see his article, "The Economics of Pure Communism," in the Winter 1970 edition of The Review of Radical Political Economics; for a nonradical view of such issues, see chaps. 17-20 of Peter Wiles's The Political Economy of Communism (Cambridge, Mass.: Harvard University Press, 1962). 
6. Michael Zweig, "New Left Critique of Economics," Review of Radical Political Economics 3, no. 2 (July 1971): 68.

7. In a somewhat harshly overstated manner, Robert Solow attributes to John Kenneth Galbraith the view that, "in the absence of persuasion, reduced to their already satiated biological needs for guidance, consumers would be at a loss; total consumer spending would fall and savings would simply pile up by default." If that view should be correct, hippie attitudes toward consumption would be more common were it not for advertising and for advertisers' control over the characteristics of the milieu-creating media. Solow's assertion can be found in "The New Industrial State or Son of Affluence,'” Public Interest 9 (1967): 104.

8. Arrow, "Extension of the Basic Theorems."

9. Gale, "Law of Supply.",

10. Ibid., p. 161. Gale's theorem does permit "just-satiating" income in equilibrium and "supersatiating" income out of equilibrium.

11. Quirk and Saposnik have used Arrow's model in an extensive discussion of the effects of bliss on Pareto optimality. Their rejection of Gale's illustration appears to be based upon the imputation to Gale of Arrow's definitions and assumptions. See Quirk and Saposnik, Introduction, chap. 4.

12. Precluding savings and restricting discussion to one time period, stationarity is assumed to permit illustration in two dimensions. When considering more dimensions than can be displayed geometrically, one can incorporate savings, investment, and growth into the discussion by adopting the conventions explained by Gerard Debreu in his Theory of Value (New York: John Wiley \& Sons, 1959), pp. 28-36.

13. Although the Edgeworth box diagram is commonly used to illustrate the allocation of wealth, much of the discussion in this article is understood most easily in terms of the allocation of income. In that case, the endowment can be viewed as single-period income paid in gcods.

14. Although the illustrated equilibrium is not unique, it is attained through highly plausible behavior. Alternatively, suppose Mr. A were to attempt to move directly from point $E$ to point $Q$ through market transactions; that is, suppose he were to demand his bliss point at the market. The rate of exchange that would characterize such a transaction would be the slope of the line from $E$ to $Q$. Since that rate differs from the market price ratio, he would not be acting as a price taker. If desired, uniqueness of the illustrated equilibrium could be established by assuming that good $Y$, tattoos, for example, is nondisposable.

15. The weak form of the budget constraint also could be viewed as a conclusion, but only within the context of a much more general model than that postulated by Arrow. Such a model would deal with questions of freedom, power, and the evolution of economic institutions and systems. Insight into these issues and their implications can be acquired from Warren Samuels's “Welfare Economics, Power, and Property," in Gene Wunderlich and W. L. Gibson, Jr., Perspectives of Property (University Park: Institute for Research on Land and Water Resources, Pennsylvania State University, 1972), pp. 61-148. Also see Zweig, "New Left," p. 68.

16. The weak (inequality) form of Walras's Law must and does hold even 
if markets are not in equilibrium. For the equilibrium allocation illustrated in Figure 2, the strong form of Walras's Law also holds, if demand is interpreted to be market demand rather than consumption. That result follows, since all markets have been shown to be cleared; hence the value of excess supply in each individual market is zero.

17. Although more difficult to illustrate, the conclusion is unchanged when initial stocks of the consumer good are assumed to exist.

18. For the purist who might wish to deal with preferences having "nicer" properties, a conventional bliss point could be used. The rest of the argument would be the same, since in each case discussed below the owner will choose his bliss consumption bundle.

19. Although the details of management procedures are not relevant to economic theory, one conclusion about administrative policy is dictated by the theory of the firm in Figure 4, which results from the model's behavioral assumptions. Any managerial system that would generate just-satiating profits is equally in agreement with the model's assumptions as one that generates supersatiating profits; if acquired, excess profits could be discarded by the owner at no cost. Since the owner will be at bliss in either case, his employee could own nothing of any value to his employer. Hence the employee could have no means to influence the owner to provide (or not to provide) rewards or incentives for profits in excess of satiation.

20. As discussed below, if profit maximization were assumed, essentially the same result would obtain following the owner's disposal of unwanted goods.

21. One might expect that the existence of inefficiency in equilibrium reflects an excess supply of some factor in terms of real efficient units rather than nominal units. Here one finds an illustration in the factor market of a phenomenon previously related solely to the market for consumption goods. With labor in Figure 4 measured in efficient units, the market for labor is cleared. The satiation of the owner permits the inefficient use within his firm of those units over which he has purchased control at the market. The market system is unaware of the firm's internal "excess supply" of labor. Also observe that the internal inefficient use of labor need not imply its overpayment relative to the disutility of work. The unpleasantness of repetitive, misdirected, or useless work can be at least as great as that of fully productive labor.

In applications, consideration of the internal underutilization of capital is more revealing than that of labor. Again the market remains cleared, with zero capital supplied at the market at all capital prices.

22. It also can be shown that one market equilibrium can be Pareto superior to another: Choices between some equilibria can be made through the utilization of the Pareto optimality criterion. For example, market equilibria Pareto superior to the allocation under consideration could be illustrated by raising the wage rate in Figure 4 . As in the pure exchange example, the point is that the efficient allocation, far from being unique, is one among an uncountable number of inefficient equilibria, between which the model can discriminate only if deviations from some assumptions are permitted.

23. The term market equilibrium will be used solely with respect to a private 
ownership economy devoid of any governmental intervention.

24. Tjalling C. Koopmans, Three Essays on the State of Economic Science (New York: McGraw-Hill, 1957), p. 66.

25. Note that the productive inefficiency that may obtain when the owners of a firm have achieved economic bliss need not result in the existence of low profits. Each firm in such models is presumed to own a scarce resource, say, downtown land, fertile agricultural land, a patent, or perhaps exceptional entrepreneurial ability. The quantity and scarcity of such factors owned may be great. With profits in this model being the rent to these factors, efficient exploitation of scarce factors may not be required to achieve seemingly high profits. Since the stockholders or their ancestors may have paid dearly for these resources, the yield on the original investment may be low; but despite his past sacrifices, or the past sacrifices of his ancestors, or perhaps the past sacrifices of his nation's victorious invading armies, he is now at bliss.

26. Harold Hochman and James Rodgers have demonstrated the need for moderate income redistribution to achieve Pareto optimality when preferences exhibit charitableness. But without redistribution, the original inefficient equilibria become efficient when preferences are selfish; their conclusions depend upon the existence of externalities in consumption and therefore formally are unrelated to the proof of Arrow's theorem. See th $\rightarrow$ "'Pareto Optimal Redistribution," American Economic Revie:v 59, no. 4 (September 1969): 542-57. For further discussion see their observations and those of others $\rightarrow$ American Economic Review 60, no. 5 (December 1970): 988-1002.

27. Envy could be incorporated formally into the illustrations by assuming that increased consumption by others shifts down one's utility function without changing the shape of the indifference curves, that is, that an envy component monotonically decreasing in the consumption of others is added onto one's utility function. Since the consumption of others would result only in the relabeling of one's indifference curves, the geometry of the diagrams would be unchanged. The previously illustrated inefficient allocations not only would be market equilibria but also would be unique.

28. The controversial sociological view relating industrialization to Protestantism is contained in Weber, The Protestant Ethic.

29. The existence of such hoarded savings concomitant with the existence of high interest rates could be viewed as evidence of extreme risk aversion rather than of satiation. Since the most "insatiably" acquisitive entrepreneurs tend in reality to be the most aggressive risk takers, to postulate extreme risk aversion on the part of one who can easily afford risk is to provide little more than an overly complicated explanation of a simple phenomenon: satiation. With regard to the merits of such overly involved ad hoc theories, refer again to footnote 3 on Friedman's discussion of valid methodology.

30. Some may believe that the source of the unfavorable performance of traditional Third World societies is the leisure choice of the wealthholding class. If that explanation should be correct, the wealthy must possess a monopoly on skills that cannot be acquired through any amount of education or experience. Otherwise, unlimited leisure could be acquired 
by the wealthholding class through the delegation of managerial responsibility to professionally educated and trained administrators.

Furthermore, the explanation cannot be found in time-preference considerations. The problem of such economies is not that of accumulating enough savings, but that of channeling already existing savings into the most productive capital investments. See, for example, John Maynard Keynes, The General Theory of Employment Interest and Money (New York: Harcourt, Brace \& World, 1935), p. 337; also see Milton Friedman, A Theory of the Consumption Function (Princeton: Princeton University Press, 1957), p. 236.

31. Joseph A. Schumpeter, Capitalism, Socialism, and Democracy(New York: Harper \& Row, 1950), p. 160. On p. 113, Schumpeter stated his basic question on the distant future: "For every given state of human wants ... . there is . . . a definite amount of fixed and circulating capital that will spell saturation. ... But is it not conceivable that wants may some day be so completely satisfied as to become frozen forever after?" A similar view was expressed more strongly by Keynes in his Essays in Persuasion (New York: Norton \& Co., 1963), pp. 366-69.

32. Stated equivalently, the private ownership economy does not exhibit the property of efficiency. Arrow's famous converse theorem demonstrates under substantially stronger assumptions that the private ownership economy does possess the property called unbiasedness. The two proofs are independent. Furthermore, Arrow's proofs deal with a laissez-faire, perfect market economy in which a rigid allocation of wealth is part of the economy's definition; but unbiasedness relates to the efficacy of externally imposed wealth redistribution. Hence, unbiasedness deals with actions exogenous to the existing economy-actions, in fact, defining a new laissez-faire "economy." Efficiency, on the other hand, is an inherent property characterizing the operation of an economy free from external intervention. The present article is unrelated to Arrow's proof of unbiasedness and is not intended to contradict that proof. 